\title{
Containing contraceptive costs
}

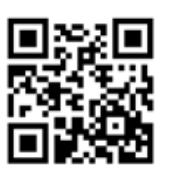

There are about 7 billion people living on our planet. In many countries resources are strained and we seek to slow down the rate of population growth. There are obviously many factors that lead to rapid population growth. Contraceptive methods are an important means of slowing population growth by helping people limit and/or space their families. While the cost of older methods such as the oral contraceptive pill, injectable progestogens and copper intrauterine contraceptive devices (IUCDs) has come down considerably, the cost of the newer hormone-based long-acting reversible contraceptive (LARC) methods has not.

It is now generally accepted that LARC methods are most effective in preventing unwanted pregnancy, because their use does not demand daily compliance. ${ }^{[1]}$ While the copper-based IUCDs remain effective and are very cost-effective, they generally have more side-effects (including excessive bleeding) than the subdermal etonogestrel-based implant (Implanon) and levonorgestrel-based Norplant, and the levonorgestrel intrauterine systems (IUSs) Mirena and Skyla/Jaydess (the latter not currently available in South Africa). Use of the Implanon and Mirena is increasing and bringing with it increased costs to both government and third party and individual payers. Are we paying too much - not because the manufacturer is overcharging, but because we are not fully utilising the lifetime of these products?

The evidence that copper IUCDs can be used well beyond their registered lifetimes is not new. ${ }^{[2]}$ While there are practical costs associated with changing these products at the specified intervals, and attendant clinical risks, it is with the hormone-based LARC methods that the potential savings are greatest. Unlike copper IUCDs, which in some countries are very cheap, the hormone-based LARCs are universally expensive. A new study from St Louis, USA, has evaluated using the Mirena for an extra year beyond its recommended lifetime. ${ }^{[3]}$ A total of 263 women completed an additional 197.7 woman-years of follow-up. There was one pregnancy, giving a failure rate of $0.51 \%$ ( $95 \%$ confidence interval $0.01-2.82$ ). The etonogestrel implant was also evaluated for an additional year by measuring serum etonogestrel levels. The median and range of etonogestrel levels were $188.8 \mathrm{pg} / \mathrm{ml}(63.8-806.6)$ at 3 years of use, and $177.0 \mathrm{pg} /$ $\mathrm{ml}(67.9-470.5)$ at 4 years. Etonogestrel levels were unrelated to body mass index. This supplements a previous clinical study of the etonogestrel implant beyond 3 years of use. ${ }^{[4]}$

The situation with the Mirena is interesting in that it contains $52 \mathrm{mg}$ of levonorgestrel. Initially the release rate of levonorgestrel is $\sim 20 \mu \mathrm{g} / \mathrm{d}$, declining to $\sim 10 \mu \mathrm{g} / \mathrm{d}$ at the end of its 5 -year lifespan. The Skyla/Jaydess contains $13.5 \mathrm{mg}$ of levonorgestrel, which is initially released at the rate of $\sim 10 \mu \mathrm{g} / \mathrm{d}$, declining to $\sim 5 \mu \mathrm{g} / \mathrm{d}$ at the end of its 3-year lifespan. In the USA the Skyla is promoted as a 'low-dose' IUS for women and healthcare providers who think that the Mirena is capable of producing side-effects such as weight gain, depression, mood swings, acne and fluid retention. In reality, its narrow presenting diameter allows it to negotiate the nulliparous cervix easily and its smaller frame fits the smaller nulliparous uterine cavity. ${ }^{[5]}$ If the Skyla IUS remains effective at a release rate of $5 \mu \mathrm{g} / \mathrm{d}$, it is logical to assume that the Mirena would as well. This suggests that the Mirena may be fully effective well beyond its current 5 -year lifespan. The good news is that women who delay or fail to return for follow-up are likely to be protected against pregnancy for a considerable time, and that if they desire a pregnancy they will present for removal of the device. The dilemma remains for the clinician who sees users who return timeously. She/he is trapped between the Scylla of wanting to save the patient or the third-party payer a substantial sum of money, and the Charybdis of complying with the licence specifics of the product.

How do we explain to our method users that the lifespan of these products is really fairly arbitrary, and that the manufacturer evaluates safety and efficacy for a certain timespan that seems reasonable? The process of testing to find the near limit of any medical products utility would be time consuming, expensive and unethical. When independent evidence emerges that a product lifespan is indeed longer than the licence dictates, manufacturers rarely go to the expense of getting a new licence, especially if it is against their financial interests. Wu and $\mathrm{Pickle}^{[2]}$ provide some controversial guidelines for the extended use of IUCDs. In the end, as always, clinicians have to use their clinical judgement. We should replace the device for users who seem concerned, and support users who request extended use either because they have heard about it elsewhere or because it is suggested to them. Some will be natural candidates for extended use, either because they are older and have declining fertility or because they are considering the use of another method or sterilisation.

While existing manufacturers are unlikely to make changes to their existing products, if the experience of the copper-based IUCDs over the past 40 years is repeated, new and generic manufacturers will use these new data in order to capture market share. Cheaper and longeracting hormonal LARC methods are on the way.

\section{Norman David Goldstuck}

Department of Obstetrics and Gynaecology, Faculty of Medicine and Health Sciences, Stellenbosch University and Tygerberg Hospital, Cape Town, South Africa

\section{Corresponding author: N D Goldstuck (nahumzh@yahoo.com)}

1. Winner B, Peipert J, Qiuhong Zhao MS, et al. Effectiveness of long-acting reversible contraception. N Engl J Med 2012;366(21):1998-2007. [http://dx.doi.org/10.1056/NEJMoa1110855].

2. Wu J, Pickle S. Extended use of the intrauterine device: A literature review and recommendation for clinical practice. Contraception 2014;89(6):495-501. [http://dx.doi.org/10.1016/j.contraception.2014.02.011]

3. McNicholas C, Maddipati R, Qiuhong Zhao MS, Swor E, Peipert JF. Use of the etonogestrel implant and levonorgestrel intrauterine device beyond the U.S. Food and Drug Administration-approved duration. Obstet Gynecol 2015;125(3):599-604. [http://dx.doi.org/10.1097/AOG.0000000000000690]

4. Affandi B, Korver T, Paul-Guerts TB, Bennink HJT. A pilot study with a single rod implant (Implanon ${ }^{\circ} 1$ ) 4. Affandi B, Korver T, Paul-Guerts TB, Bennink HJT. A pilot study with a single rod i
in 200 Indonesian women treated for 4 years. Contraception 1999;59(3):167-174.

5. Steyn PS, Goldstuck ND. Contraceptive needs of the adolescent. Best Pract Res Clin Obstet Gynaecol 2014;28(6);891-901. [http://dx.doi.org/10.1016/j.bpobgyn.2014.04.012]

S Afr Med J 2015;105(4):286. DOI:10.7196/SAMJ.9480 